\title{
Ilha de Calor Urbana e desconforto térmico: uma análise episódica em Cuiabá/MT ${ }^{1}$
}

\author{
Aristóteles Teobaldo Neto ${ }^{(1)}$, Margarete Cristiane de Costa Trindade Amorim ${ }^{(2)}$ \\ ${ }^{(1)}$ Instituto Brasileiro de Geografia e Estatística - IBGE \\ Rua Cel. Peixoto, 17. Praça Bispo Dom José, Centro, Cuiabá, MT, Brasil \\ teobaldoneto2010@gmail.com \\ ${ }^{(2)}$ Universidade Estadual Paulista FCT/UNESP \\ Rua Roberto Símonsen, 305 - Centro Educacional, Pres. Prudente - SP, 19060-900Presidente Prudente, SP, Brasil, \\ mccta@fct.unesp.br
}

\section{Eixo: Climatologia em diferentes níveis escalares: mudanças e variabilidades.}

Resumo

\begin{abstract}
A forma como o espaço urbano é produzido e reproduzido, é responsável pela elevação das temperaturas a tal ponto de criar o conhecido fenômeno Ilhas de Calor Urbana (ICU), responsáveis pelo desconforto térmico. Ainda que o desconforto possa se espacializar de forma homogênea, os seus efeitos serão percebidos de forma diferenciada, de acordo com o nível de vulnerabilidade social. A partir da teoria da Geografia do Clima, foi pautado o objetivo de diagnosticar a ICU e dimensionar o Conforto Térmico, bem como explicar como a produção desigual do espaço urbano de Cuiabá MT, implica em diferentes formas de ser impactado pelo desconforto térmico. No ensaio experimental, foi demonstrado como a variável da vulnerabilidade (renda) é determinante na explicação de quem é mais vulnerável aos altos níveis de desconforto térmico.
\end{abstract}

Palavras chave: Clima Urbano, Conforto Térmico, Geografia do Clima.

\section{O clima urbano como fator de risco}

As altas temperaturas, assim como suas variações bruscas são características cada vez mais frequentes não só nas cidades brasileiras, mas em todo o planeta. A NASA² (2016) declarou que o ano de 2015 foi o mais quente da história. A média da temperatura do planeta foi a mais alta já registrada desde o início da medição das temperaturas na superfície da Terra, em 1880. A informação foi confirmada pela NationalOceanicandAtmosphericAdministration (NOAA), que realizou análises independentes. O fato de a NASA confirmar que desde 2001, ocorreram 15 dos 16 anos mais quentes já registrados na história, confirma a tendência ao aquecimento.

A maior parte das cidades brasileiras está inserida em ambientes de clima tropical, cuja principal característica são as altas temperaturas durante a maior parte do ano. A forma como o espaço urbano é

\footnotetext{
${ }^{1}$ Este artigo apresenta parte dos resultados da pesquisa de doutorado intitulada: "Clima Urbano em Cuiabá/MT: A dimensão do risco em áreas de alta Vulnerabilidade Socioespacial"

${ }^{2}$ NationalAeronauticsand Space Administration
} 
produzido e reproduzido, agrava esta condição natural, elevando as temperaturas a tal ponto de criar o conhecido fenômeno Ilhas de Calor Urbana (ICU), que representa, entre outros, um problema ambiental que merece atenção de cientistas e planejadores urbanos, tendo em vista a ameaça que representa para o meio ambiente urbano e seus cidadãos, conforme aponta Amorim:

Práticas como a impermeabilização dos solos, a utilização de materiais construtivos inadequados, a retirada da cobertura vegetal original, a canalização fechada de rios e córregos, a emissão de poluentes para a atmosfera têm sido frequentes nas cidades. Essas modificações associadas às características naturais dos ambientes tropicais têm proporcionado a geração de ilhas de calor e têm sido registradas situações de desconforto térmico na maioria das cidades onde os estudos têm sido realizados. (2010, p. 72)

\section{As Ilhas de Calor Urbana e o Conforto Térmico}

A ilha de calor é uma anomalia térmica com dimensões horizontais, verticais e temporais, que tem sido observada em quase todos os assentamentos estudados. Suas características estão relacionadas com a natureza da cidade (tamanho, densidade de construções, uso do solo) e com as influências externas (clima, tempo e estações) (Oke, 1978).

Lombardo (1985, p. 24), que estudou o mesmo fenômeno na escala das metrópoles, tendo São Paulo como estudo de caso, define:

A Ilha de calor urbana corresponde a uma área na qual a temperatura da superfície é mais elevada que as áreas circunvizinhas, o que propicia o surgimento de circulação local. O efeito da ilha de calor sobre as cidades ocorre devido à redução da evaporação, ao aumento da rugosidade e às propriedades térmicas dos edifícios e dos materiais pavimentados.

Fialho (2012, p. 61), aponta que a diferenciação da superfície urbana, em relação ao campo, "acarreta uma diferença no tempo de absorção da energia solar disponível durante o dia e da reemissão da energia terrestre à noite. A consequência deste novo balanço de energia é o resfriamento mais lento da cidade, após o pôr-do-sol". Por isso, o fenômeno é mais intenso no período noturno.

Oke (1978) e Arnfield (2003), reconhecem 3 tipos de ICUs, amplamente aceitas no meio científico: 1. atmosférica inferior, 2.atmosférica superior e 3.superfície. A ICU de superfície está relacionada à radiação emitida pelos alvos da superfície terrestre, que podem ser traduzidos em valores de temperatura a partir da conversão dos valores de radiância das imagens obtidas por sensores remotos, na faixa espectral infravermelho termal, a bordo de satélites, como o Landsat8. 
XVII Simpósio Brasileiro

de Geografia Fisica Aplicada

I Congresso Nacional

de Geografia Física
OS DESAFIOS DA GEOGRAFIA FÍSICA NA FRONTEIRA DO CONHECIMENTO

Instituto de Geociências - Unicamp

Campinas - SP

28 de Junho à 02 de Julho de 2017

No plano vertical, formam-se duas camadas: a UrbanCanopyLayer UCL (inferior) e

UrbanBoundaryLayerUBL (superior). A UCL está situada entre o solo e o nível médio dos telhados (coberturas). De acordo com Oke (1978) ela é produzida por processos que ocorrem na microescala e possui uma complexidade característica, devido à diversidade das atividades na superfície. $\mathrm{O}$ fenômeno da urbanização é a causa desta camada de calor que, por sua influência, no plano vertical, dá origem à UrbanBoundaryLayer - UBL (Camada Limite Urbana). Trata-se da camada localizada sobre a UCL. Suas dimensões variam no tempo e no espaço, sendo mais espessa de dia e mais compacta à noite.

Oke (1978) traçou um perfil vertical geral, de uma típica ICU em situação de céu sem nuvens, ventos fracos, após o pôr do sol em uma cidade grande. Partindo da periferia rural, adentrando na cidade, passando pelo centro comercial até o lado oposto rural. No esquema cartesiano ilustrado na Figura 1, observa-se o aumento da temperatura na medida do deslocamento para o centro comercial e o decréscimo, no sentido contrário, formando uma morfologia análoga a uma ilha. "The differencebetweenthesvalueandthe background rural temperature defines theurbanheatislandintensity" (OKE, 1978).

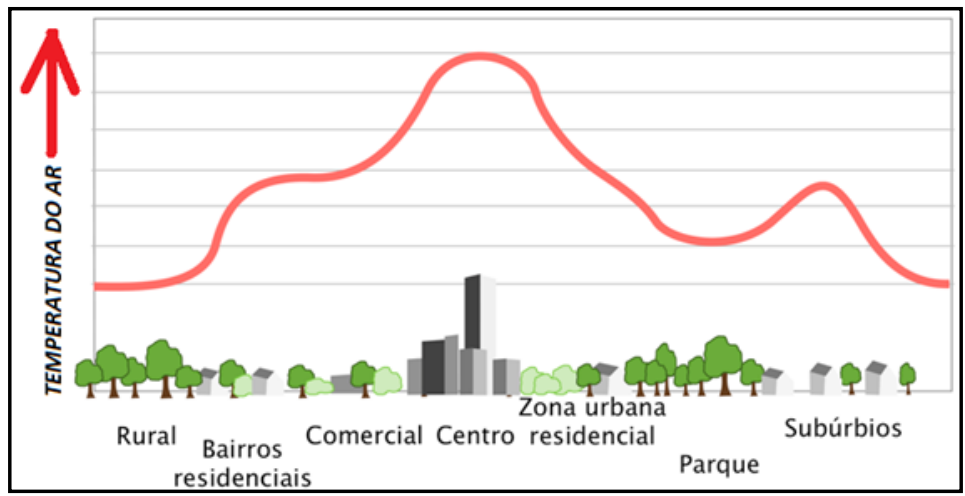

Figura 1 - Perfil de uma típica Ilha de Calor Urbana.

Fonte: Adaptado do esquema de Oke (1978) e http://geofacinfacin.blogspot.com.br/

Apesar de não ser o único, o desconforto térmico é o efeito mais evidente, que interfere diretamente na qualidade de vida das pessoas. Nas ciências biológicas, o ser humano é classificado entre os animais homeotérmicos. São aqueles que mantém a temperatura do corpo constante, independente da temperatura ambiente. "Sob uma variedade de condições físicas e ambientais, o equilíbrio entre a produção e a perda do calor, que é resultante da ação dos centros termorreguladores, mantém a temperatura corporal em níveis estáveis, ou seja, em torno dos $37^{\circ} \mathrm{C}$.” (CAMARGO e FURLAN, 2011, p.279). Caso haja alteração da situação física ou ambiental, por exemplo, quando o corpo é exposto a situações extremas de frio ou calor, fora da zona de conforto térmico, o organismo aciona mecanismos termorreguladores que garantam a temperatura interna em nível estável, no patamar de 37 oC. 


\section{OS DESAFIOS DA GEOGRAFIA FÍSICA NA FRONTEIRA DO CONHECIMENTO \\ Instituto de Geociências - Unicamp \\ Campinas - SP \\ 28 de Junho à 02 de Julho de 2017}

Emresposta a temperaturasambientaiselevadasouaocalorproduzidoporexercício, a produção de suorproveniente das glândulassudoríferasécrinasaumenta; aevaporaçãodo suor da superfície da peleajuda a baixar a temperatura do corpo. Emresposta a baixastemperaturasambientais, a produção de suor das glândulassudoríferasécrinasdiminui, ajudando a conservar o calor.Além disso, osvasossanguíneosnaderme se contraem (se estreitam), o quediminui o fluxosanguíneo e reduz a perda de calor do corpo. (TORTORA e DERRICKSON, 2017, p. 107)

Muitos autores definem o conforto térmico como o estado de bem-estar, quando o organismo não necessita acionar mecanismos termorreguladores para manter a temperatura corporal estável. Para Garcia (1985, p. 199), consiste no conjunto de condições em que os mecanismos de autorregulação são mínimos, ou ainda na zona delimitada por características térmicas em que o maior número de pessoas manifeste se sentir bem.

De acordo com Frota e Schiffer (2001), as variáveis ambientais que determinam o conforto térmico são: temperatura, umidade, velocidade do ar e radiação solar incidente. A diversidade de fatores ambientais, bem como, as particularidades individuais, de cunho orgânico, são suficientes para compreender a dificuldade de estabelecer parâmetros definidores do conforto térmico. Há duas maneiras de se avaliar se o ambiente está termicamente confortável: a subjetiva, a partir da avaliação da percepção pessoal e a objetiva, a partir dos mais diversos índices de conforto térmico."A maioria dos métodos utilizados para analisar os índices de conforto térmico dapopulação brasileira está baseada nas preferências térmicas da população de latitudes médias" (SOUZA e NERY, 2012, p. 65). Apesar disso, o índice de temperatura efetiva de Thom e Bosen (1959), tem sido usado em muitas pesquisas em ambientes tropicais, com boa aceitação. Gomes e Amorim (2003), usou para avaliação de praças públicas e Vianna (2013), usou para avaliação de escolas estaduais, em Presidente Prudente/SP.

Tendo em vista a possibilidade de se dimensionar o impacto causado pela ICU na qualidade de vida urbana, por meio dos indicadores de conforto térmico, resta explorar a dimensão social do fenômeno. Na Geografia tem sido construído um método de estudo que seja capaz de explicar o clima que é produzido pelo fato urbano, em seu dinamismo, multiescalaridade, bem como sua interação com o clima regional e global. Para responder à natureza complexa deste clima, eminentemente urbano, novas propostas metodológicas surgiram no seio da ciência geográfica, como será abordado no próximo tópico.

\section{A Geografia do Clima: um novo paradigma na análise geográfica do clima.}

O marco paradigmático iniciou-se com as contribuições do geógrafo francês, MaximilienSorre (1943), influenciado pelo possibilismolablachiano, apesar de "não desconsiderar a importância do uso dos valores médios nem do emprego da estatística nos estudos climáticos" (Sant’Anna Neto, 2008, p. 54), criticou o 
XVII Simpósio Brasileiro

de Geografia Fisica Aplicada

I Congresso Nacional

de Geografia Física
OS DESAFIOS DA GEOGRAFIA FÍSICA NA FRONTEIRA DO CONHECIMENTO

Instituto de Geociências - Unicamp

Campinas - SP

28 de Junho à 02 de Julho de 2017

exagero dado aos valores médios das definições clássicas e deu relevância ao ritmo e à sucessão do tempo, meio pelo qual seria possível compreender o clima. "Sob este aspecto, o autor não poupava críticas às propostas de classificação de Köppen, nem de DeMartonne, tanto pelo empirismo empregado, quanto pela impossibilidade destas classificações de conciliar uma definição dinâmica dos climas, pois se pautava em definição estática" (Sant’Anna Neto, 2008, p. 54).

Assim foram criadas as bases para que, na Geografia brasileira, Monteiro (1976), inspirado no trabalho de Sorre (1943), elaborasse uma metodologia de análise do clima que valorizasse o dinamismo da atmosfera que não pode ser representado por uma classificação estática, tendo em vista as suas vicissitudes em todas as escalas: globais, regionais, diárias e, até mesmo, horárias. Além disso, foi considerado que, apesar de a atmosfera repetir estados atmosféricos de forma periódica, da mesma forma, pode sofrer alterações que podem implicar em eventos extremos, totalmente fora do padrão. Assim, criou a teoria do Ritmo Climático (1971) e, posteriormente, do Sistema Clima Urbano SCU (1976). Para melhor compreensão do SCU, o autor sugere a adoção de três subsistemas tendo-se como referência os canais de percepção humana, conforme demonstrados na Figura 2.

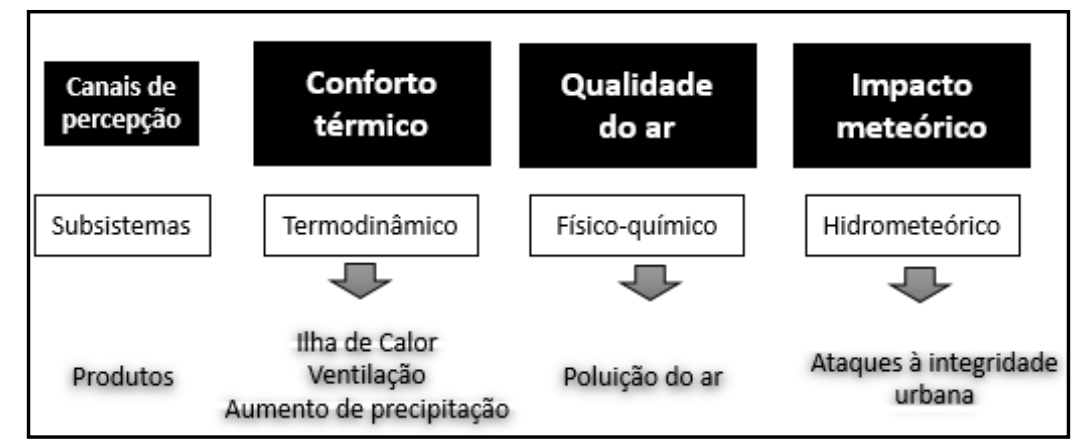

Figura 2 - Sistema Clima Urbano: Articulação dos sistemas segundo os canais de percepção: subsistemas e produtos

Fonte: Adaptado de MONTEIRO, 1976.

O legado Monteriano possibilitou à Geografia uma melhor explicação do Clima Urbano, tendo em vista a complexidade inerente à dinâmica das cidades, em suas mais variadas dimensões. Sua teoria influenciou não somente a Geografia, mas outras áreas que estudam o Clima Urbano, como Meteorologia, Engenharia Civil, Física Ambiental, Engenharia Urbana, Arquitetura e Urbanismo, entre outras.

Apesar do importante legado, Sant'Anna Netto, (2001, p.55) afirma que a análise geográfica do clima que se tem praticado, baseada no tripé ritmo climático - ação antrópica - impacto ambiental apresenta limitações, na medida em que "a concepção de ação antrópica, além de demonstrar uma visão extremamente naturalista da relação sociedade-natureza, tende a minimizar os aspectos de ordem social, econômica e ideológica do processo de intervenção e apropriação dos recursos naturais". O autor coloca 
em pauta a categoria geográfica do espaço e o conceito da produção do espaço urbano, conforme as contribuições de Milton Santos (2001), David Harvey (2005) e Henri Lefebvre (2006) que destacam as diferentes intenções dos diferentes atores sociais na produção do espaço urbano. Sant'Anna Netto (2001), ilustra a necessidade de se incorporar a dimensão social na interpretação do clima:

O efeito dos tipos de tempo sobre um espaço construído de maneira desigual gera problemas de origem climática também desiguais. A entrada de um sistema atmosférico, como uma frente fria (frente polar atlântica), por exemplo, se espacializa de maneiramais ou menos uniforme num determinado espaço, em escala local. Entretanto, em termos socioeconômicos, este sistema produzirá diferentes efeitos em função da capacidade (ou da possibilidade) que os diversos grupos sociais têm para defender-se de suas ações.

Nesta direção teórica é que se define o objetivo deste artigo: mapear e explicar como a produção desigual do espaço urbano de Cuiabá MT, implica em formas diferentes de sentir os efeitos adversos do clima, a partir de um ensaio experimental, considerando o canal de percepção: Conforto Térmico e a renda, enquanto variável explicativa dos efeitos da desigualdade socioespacial.

\section{Caracterização da área de estudo.}

A cidade de Cuiabá/MT faz parte da Região Metropolitana do Vale do Rio Cuiabá3 e somada a cidade de Várzea Grande/MT (conurbadas) estima-se o total de 856.706 habitantes (IBGE, 2016). A localização e características geoambientais, particulares desta localidade, são responsáveis pela elevação natural das temperaturas. Em posição geocêntrica na América do Sul, está distante da influência das massas de ar marítimas. O relevo de baixas altitudes é classificado como Depressão Cuiabana (ROSS, 1990). A média altimétrica é de aproximadamente 180 metros e a dinâmica de ventos são os fatores naturais que acentuam as altas temperaturas. (Figura 3) "Enquanto a velocidade média anual do vento em Cuiabá é de, aproximadamente, $1,5 \mathrm{~m} / \mathrm{s}$, na Chapada dos Guimarães a velocidade média fica em torno de 3,5m/s atingindo frequentemente valores de até $5 \mathrm{~m} / \mathrm{s}$ " (MAITELLI, 2005, p. 243).

\footnotetext{
${ }^{3}$ Criada em 2009 por lei estadual complementar n. 359 de 27 de maio de 2009, atualizada pela n. 577 de 19 de maio de 2016, a RMVRC é composta pelos municípios: Cuiabá, Várzea Grande, Nossa Senhora do Livramento, Santo Antônio de Leverger, Acorizal e Chapada dos Guimarães.
} 

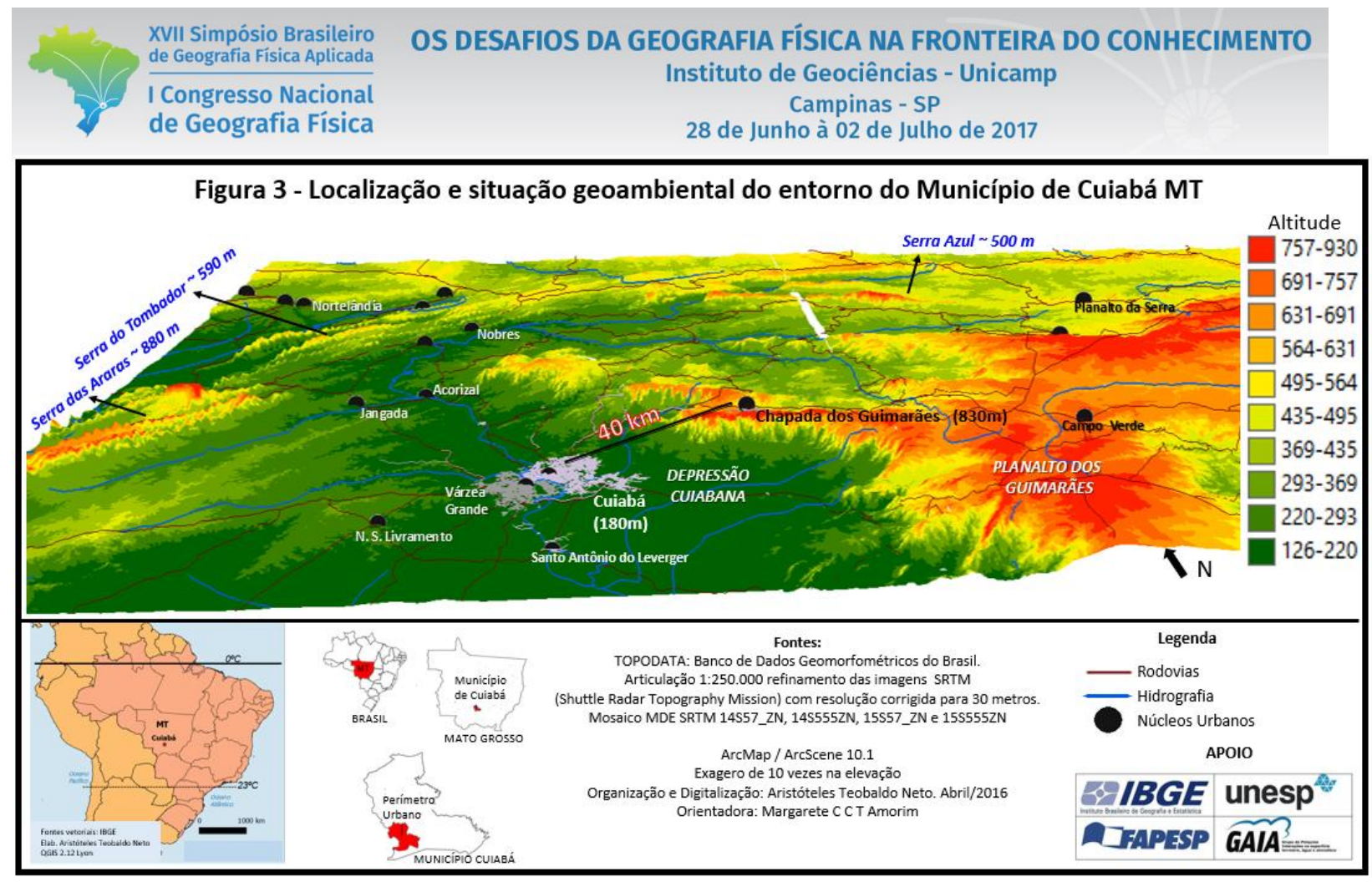

Para exemplificar a importância dessa característica natural, com uma distância inferior a 40 quilômetros, em linha reta a partir da área urbana de Cuiabá, a cidade de Chapada dos Guimarães tem uma redução natural de cinco graus na temperatura, devido à diferença altimétrica.

Os anéis rodoviários de Cuiabá e Várzea Grande são os principais canais de vazão de praticamente toda a cadeia produtiva do estado de Mato Grosso, com destino aos portos do sul e sudeste. O fluxo intenso de caminhões e carretas é relevante do ponto de vista da poluição atmosférica, mas também do aumento das temperaturas. Além disso, a supressão da vegetação natural, pavimentação asfáltica, materiais construtivos inadequados ao clima tropical, densa ocupação urbana, ocupações de áreas irregulares, são características que fazem parte do modelo de urbanização brasileira, responsável pelo aumento das temperaturas e, consequente, formação do fenômeno conhecido como Ilhas de Calor Urbanas. Pode-se afirmar que a conjugação das condições naturais e sociais potencializam e intensificam a Ilha de Calor Atmosférica em Cuiabá, tornando-a um fenômeno relevante a se considerar, tendo em vista o conforto térmico e a qualidade ambiental e de vida urbana.

\section{Procedimentos Metodológicos.}

Para atingir o objetivo do artigo, foi necessário cumprir 3 (três) etapas: 1 - pesquisa teórica; 2 levantamento de dados primários (campo); 3 - levantamento de dados secundários, tabulação, processamento e análises dos dados, conforme fluxograma síntese na Figura 4.Na primeira etapa foi feita a 


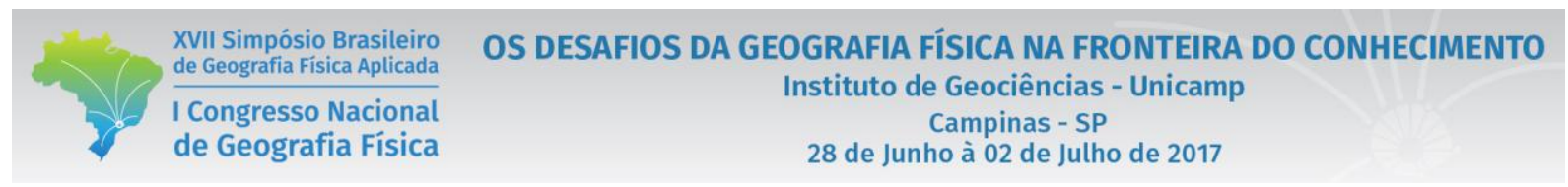

revisão da literatura básica referente aos temas: Sistema Clima Urbano, Ilhas de Calor, Geografia do Clima e Conforto Térmico. Na segunda etapa foi feito o levantamento primário de dados de temperatura e umidade relativa do ar, por meio da técnica denominada 'transectos móveis'. Essa técnica é bastante difundida em todo o Brasil. Foi feita uma adaptação a partir da metodologia utilizada por Amorim, (2005), que se baseou em Oke (1978):

A metodologiapara a coleta de temperatura do ar [...] consistenadefinição de doistransectos, com medidasmóveis, utilizando-se de termômetrosdigitais, com ossensorespresosem haste de madeira com 1,5m de comprimento, acopladosna lateral de doisveículosquesaem da periferia (rural), passandopelocentro, chegandoaoextremooposto da cidade. (AMORIM, 2005. p. 69)

\begin{tabular}{|c|}
\hline FUNDAMENTAÇÃO TEÓRICO METODOLÓGICA: \\
\hline $\begin{array}{c}\text { Sistema Clima Urbano: Canal Termodinâmico (Monteiro, 1976) } \\
\text { (Conforto Térmico e Ilhas de Calor Urbana) }\end{array}$ \\
\hline Geografia do Clima (Sant'Anna Netto, 2001) \\
\hline BANCO DE DADOS (Primários e Secundários) \\
\hline RENDA Fonte: Censo Demográfico 2010 (IBGE) \\
\hline TEMPERATURA E UMIDADE RELATIVA Do AR. Fonte: Transectos Móveis \\
\hline ínDICE DE CONFORTO TÉRMICO. Fonte: Thom, 1959 \\
\hline GeoprocesSamento QGIS: Mapa do Conforto e Renda \\
\hline ANÁLISE DOS RESULTADOS \\
\hline
\end{tabular}

Figura 4 - Fluxograma

Foram percorridos $82 \mathrm{~km}$ (quilômetros), divididos em 4 trajetos de aproximadamente $20 \mathrm{~km}$, considerados representativos da diversidade geoambiental do sítio urbano. Foram iniciados, simultaneamente, às $21 \mathrm{~h} e$ $9 \mathrm{~min}$, com velocidade entre 20 e $30 \mathrm{~km} / \mathrm{h}$, concluídos em tempo inferior a 60 minutos. Foi necessária uma equipe de 8 pessoas, sendo 4 motoristas e 4 apoiadores; 4 (quatro) Termo-Higrômetros de temperatura e umidade relativa (interna e externa), com cabo e sensor externo de 1 (um) metro, marca Incoterm; 4 (quatro) hastes de bambu; 4 (quatro) automóveis; 4 (quatro) smartphones com aplicativo de GPS Oruxmaps. O registro georreferenciado da temperatura e umidade relativa do ar foi feito a cada 200 metros, controlado pelo odômetro dos veículos. Ao final, foram coletados 417 pontos georreferenciados de temperatura e umidade relativa do ar. Na última etapa, os dados foram tabulados, processados e mapeados a partir do uso de planilha eletrônica Excel e do Sistema de Informações Geográficas (SIG) Quantum GIS4, versão 2.14 (Essen).

${ }^{4}$ O QGIS é um Sistema de Informação Geográfica (SIG) amigável, um Software Livre licenciado sob a "GNU General Public License". Trata-se de um projeto oficial da Open Source Geospatial Foundation (OSGeo). Fonte: http://qgisbrasil.org/ 
Para analisar o conforto térmico, foi selecionado o índice de Thom e Bosen (1959), que estabelece classes de conforto térmico, baseados nas temperaturas efetivas (TE), como demonstradas na Figura 5. Conforme Ayoade (1998, p .65) a temperatura efetiva pode ser obtida a partir da equação: TE = 0,4 (TS+TU) +4,8, onde TS = Temperatura de Bulbo Seco e TU = Temperatura de Bulbo Úmido. Uma planilha eletrônica5 foi elaborada com equações que possibilitaram identificar a TS, TU e TE, a partir dos dados de temperatura medida (em graus celsius) e umidade relativa do ar. No QGIS, a tabela com os registros de temperatura efetiva, georreferenciados, foi convertida em arquivo vetorial de pontos. Em seguida, os atributos dos 417 pontos georreferenciados foram classificados conforme proposta de Thom e Bosen (1959).

\begin{tabular}{|l|c|}
\hline Descrição & Classes do desconforto (TE) \\
\hline Bem estar & $\mathrm{TE}<21$ \\
Menos de 50\% da população possui um ligeiro desconforto & $21 £ \mathrm{TE}<24$ \\
Outros 50\% da população possui um crescente desconforto & $24 £ \mathrm{TE}<27$ \\
A maioria da população possui um relativo desconforto e \\
há um significativo deterioramento da condição psicofísica
\end{tabular}

Figura 5 - Distribuição das classes do conforto térmico. Fonte: Thom \& Bosen (1959)

Para fazer o mapeamento da renda, foi necessário acessar a base de dados do Censo 2010, disponível em planilhas eletrônicas nos formatos: xls e csv, disponíveis gratuitamente através do site oficial do Instituto Brasileiro de Geografia e Estatística (IBGE) http://www.ibge.gov.br/home/6. Foram selecionadas as variáveis V005, V006, V007 e V008 do arquivo "DomicilioRenda" que, somadas, correspondem ao total de domicílios particulares com rendimento mensal domiciliar de até 1 salário mínimo.

\section{Resultados}

Inicialmente, destaca-se a grande frequência dos valores extremos. Do total de 417 registros de temperaturas do ar, coletados ao longo dos 82 quilômetros, no episódio de 17/09/2016, entre 21 e 22 horas, $68 \%$ variou de 30 a $35^{\circ} \mathrm{C}$. (Tabela 1 e Figura 6).

\footnotetext{
${ }^{5}$ Elaborada e gentilmente cedida pelo Dr. José Tadeu Tommaselli (2016), professor no Programa de Pós Graduação em Geografia (acadêmico e profissional), da Faculdade de Ciências e Tecnologia - UNESP - Campus Presidente Prudente-SP

${ }^{6}$ Caminho:Canais $\rightarrow$ Projetos e Entidades $\rightarrow$ Censo $2010 \rightarrow$ Resultados $\rightarrow$ Caracteristicas da Populacao e dos Domicílios: Resultados do Universo - 16/11/11 $\rightarrow$ Agregados por Setor Censitário (tabelas xlx) ou Malha Digital de Setores Censitários (arquivos vetoriais: shp). ftp://ftp.ibge.gov.br/Censos/Censo_Demografico_2010/Resultados_do_Universo/Agregados_por_Setores_Censitarios/
} 


\begin{tabular}{|c|c|c|}
\hline \multirow{2}{*}{\multicolumn{3}{|c|}{$\begin{array}{l}\text { XVII Simpósio Brasileiro } \\
\text { de Geografia Fisica Aplicada } \\
\text { I Congresso Nacional } \\
\text { de Geografia Física }\end{array}$}} \\
\hline & & \\
\hline \multicolumn{3}{|c|}{$\begin{array}{c}\text { Tabela 1 } \\
\text { Frequência das temperaturas } \\
\text { Episódio 17/09/2016 }\end{array}$} \\
\hline $\begin{array}{c}\text { Variação } \\
\left({ }^{\circ} \mathbf{C}\right)\end{array}$ & $\begin{array}{c}\text { Registros } \\
(\%)\end{array}$ & $\begin{array}{c}\text { Registros } \\
\text { (Absoluto) }\end{array}$ \\
\hline 24 a 26 & 4,31 & 18 \\
\hline 27 a 29 & 27,33 & 114 \\
\hline 30 a 32 & 54,67 & 228 \\
\hline 33 a 35 & 13,66 & 57 \\
\hline Total & 100 & 417 \\
\hline
\end{tabular}
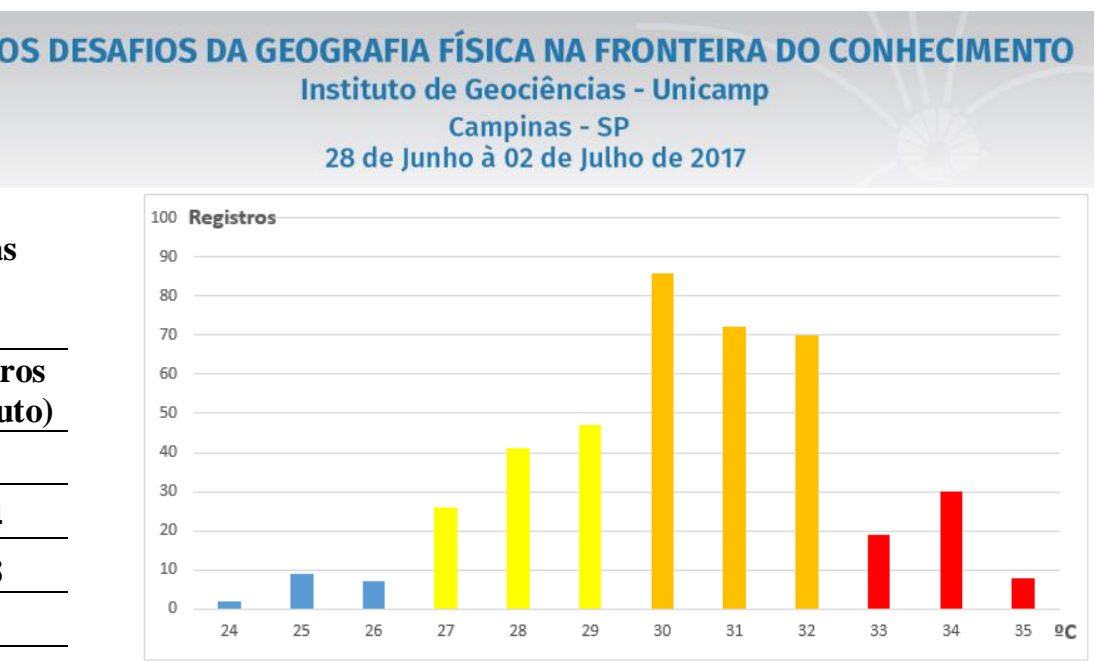

Figura 6 - Histograma da frequência das temperaturas do ar.

Quando as temperaturas absolutas são convertidas em valores de temperaturas efetivas, para fins de avaliação do conforto térmico, observa-se que o total de registros não chega a $0,5 \%$, somadas as duas classes de melhor conforto: 1 - Bem estar e 2 - Menos de $50 \%$ da população possui ligeiro desconforto.

Quase 20\% dos registros pertencem à classe 3 - Metade da população possui crescente desconforto. Já a classe 4 - A maioria da população sente crescente desconforto e há significativa deterioração da condição psicofísica, abrange quase metade dos registros. Enfim, na classe 5, onde todos possuem forte desconforto, estão 30\% dos registros. Somadas as condições mais graves (4 e 5), totalizam quase $80 \%$ dos registros, o que representa um estado crítico de conforto que ameaça a saúde da população, conforme pode ser observados na Tabela 2 e na Figura 7.

De acordo com o índice de Thom e Bosen (1959), no episódio do dia 17 de setembro, em quase 80\% do percurso os registros foram de forte desconforto com riscos à saúde. Considerando-se o percurso representativo de toda a malha urbana, totalizou-se $80 \%$ de toda a população em situação de forte desconforto. Do ponto de vista da saúde, esta situação pode implicar em doenças psicossociais, devido ao estresse, cansaço, irritação, fadiga, assim como pode agravar doenças do aparelho circulatório, respiratório e cardiovascular (ALEIXO, 2012). 


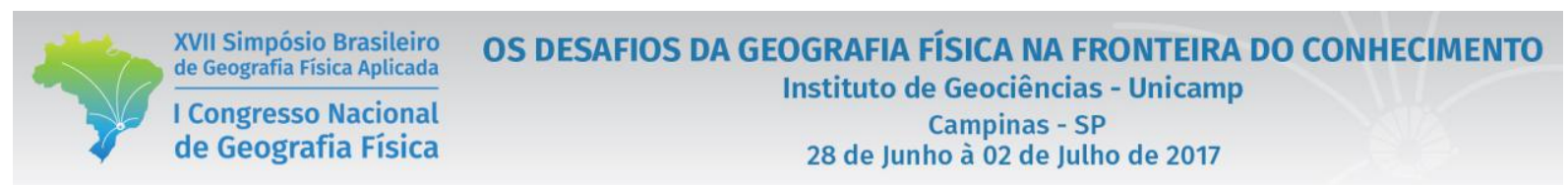

Tabela 2 - Conforto Térmico x Registros

\begin{tabular}{c|c|c} 
& Classes de Conforto Térmico & $(\%)$ \\
\hline 1 & Bem-estar & - \\
\hline 2 & $\begin{array}{c}\text { Menos de 50 \% da população } \\
\text { possui ligeiro desconforto }\end{array}$ & $\mathbf{0 , 4 8}$ \\
\hline 3 & $\begin{array}{c}\text { Metade da população possui } \\
\text { crescente desconforto }\end{array}$ & $\mathbf{1 9 , 9 0}$ \\
\hline & $\begin{array}{c}\text { A maioria da população sente } \\
\text { crescente desconforto e há } \\
\text { significativa deterioração da } \\
\text { condição psicofísica }\end{array}$ & $\mathbf{4 9 , 1 6}$ \\
\hline 5 & $\begin{array}{c}\text { Todos possuem forte } \\
\text { desconforto }\end{array}$ & $\mathbf{3 0 , 4 6}$ \\
\hline
\end{tabular}

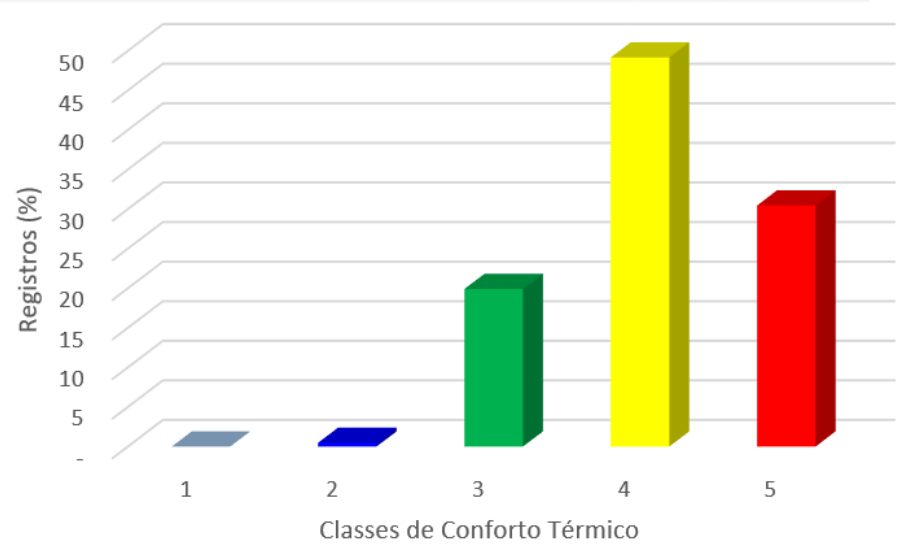

Fonte: Adaptado de Thom\&Bosen, 1959

Figura 7 - Histograma da frequência de registros de temperatura efetiva por classes de conforto térmico.

Na figura 8, está representado o mapa com a espacialização dos 417 registros, convertidos em valores de classes de conforto térmico. É possível identificar que as classes mais críticas, representadas pelas cores vermelha (5) e amarela (4), respectivamente, cobre praticamente toda a área urbanizada. As classes de melhor conforto (3 e 2), coincidem com áreas de pouca ou esparsas ocupações e edificações, geralmente associadas com densa vegetação e áreas de características rurais. Não foi identificado nenhum registro na classe 1 - Bem estar.

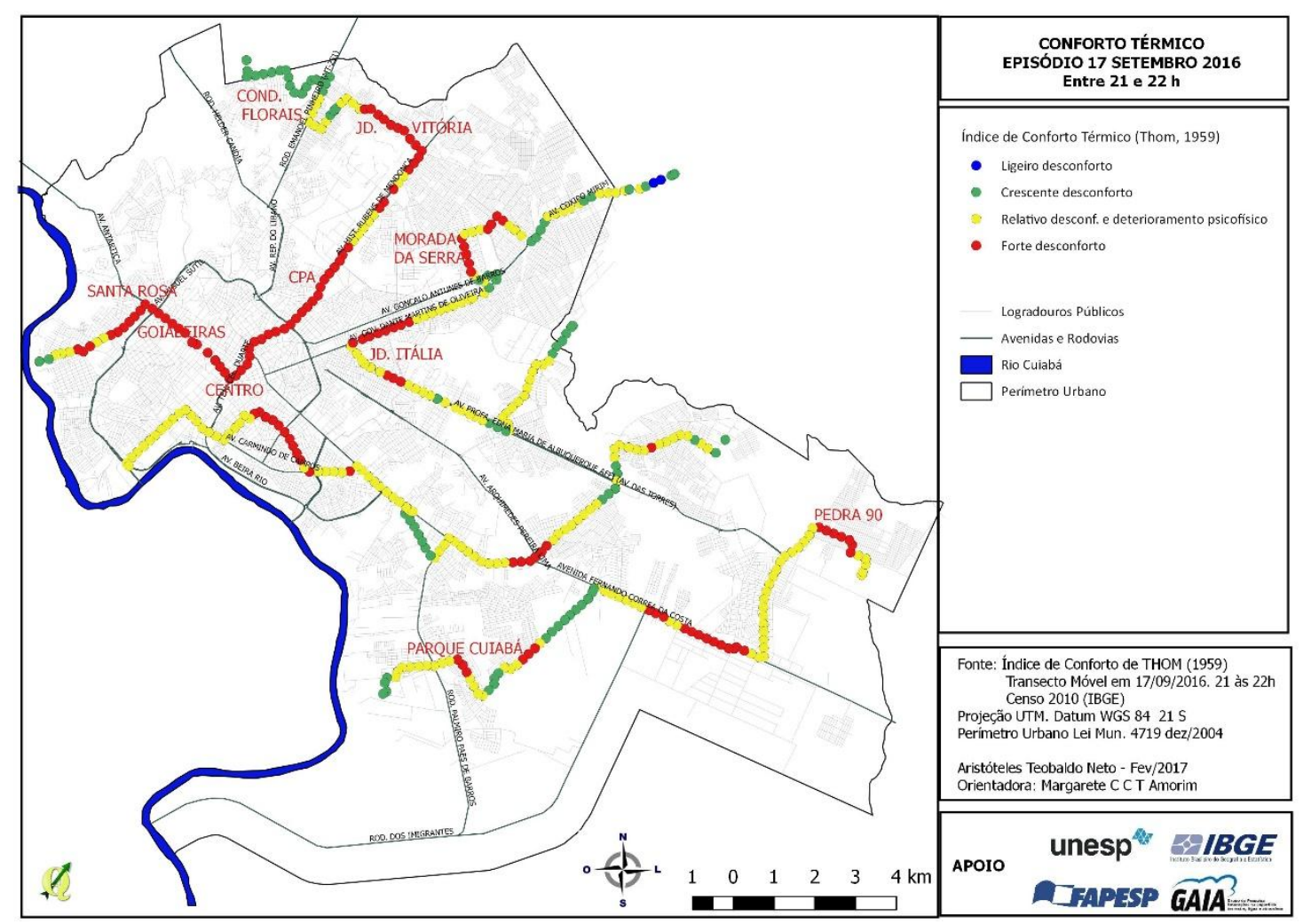

Figura 8. Mapa das classes de conforto térmico(Thom\&Bosen, 1959) 

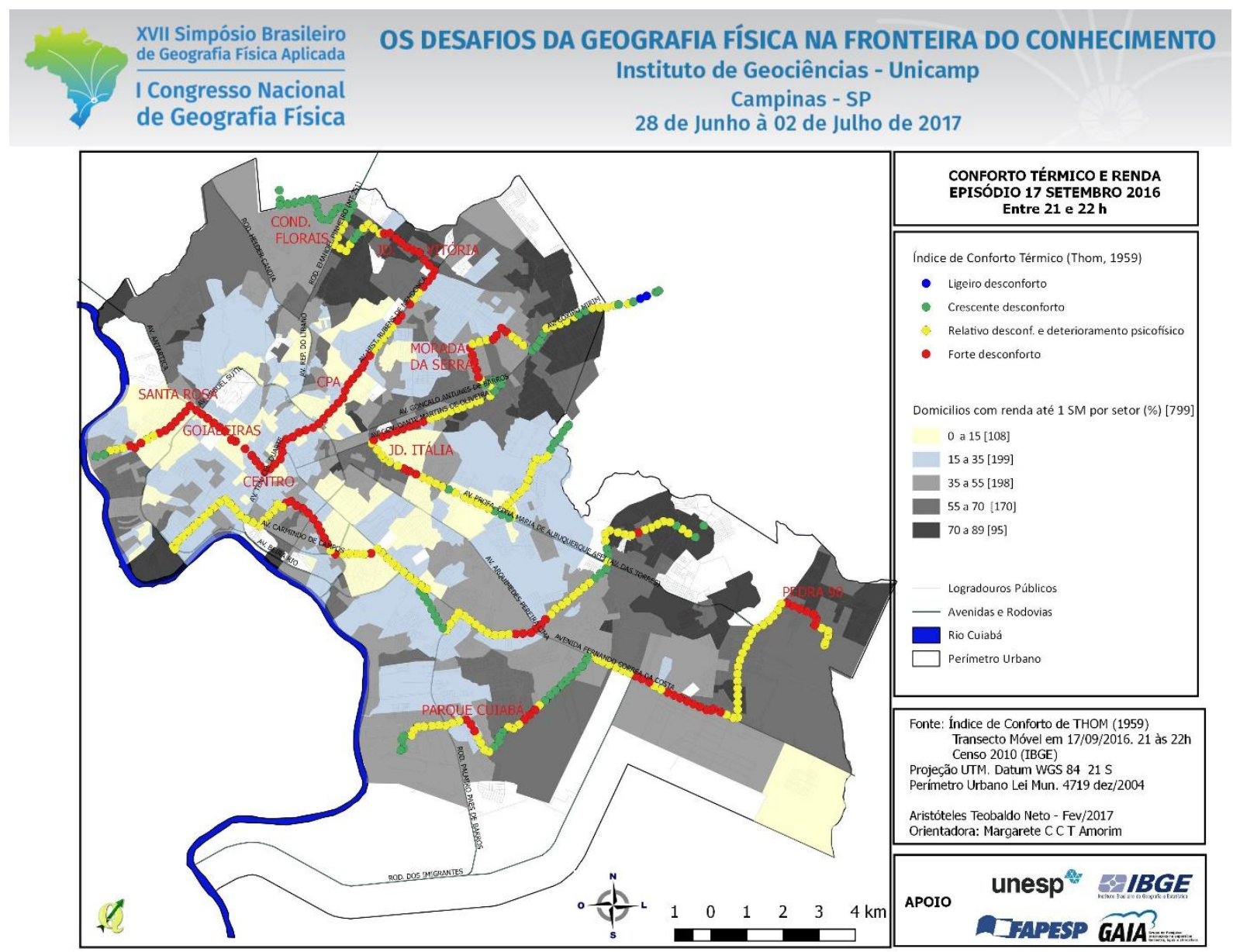

Figura 9 - Mapa das classes de Conforto Térmico x Mapa da renda.

Como demonstrado, o desconforto é generalizado na área urbana, entretanto, conforme os pressupostos da teoria da Geografia do Clima (SANT'ANNA NETTO, 2001), ainda que ele se espacializa de forma homogênea, seus efeitos serão desiguais, dependentes das condições socioeconômicas e de vulnerabilidade. Se for analisado apenas o mapa do conforto térmico, em especial a classe mais crítica do desconforto térmico, destacam-se alguns bairros: Santa Rosa, Goiabeiras, Centro, Morada da Serra (CPA), Jardim Vitória, Jardim Itália, Morada da Serra, Pedra 90 e Parque Cuiabá. Entretanto, ao observar o mapa da renda (Figura 9), com exceção do Jardim Vitória, Pedra 90 e Parque Cuiabá, todos os demais são bairros de renda alta. Nestes casos, apesar da temperatura ambiente registrar o mais alto nível de desconforto, por outro lado, suas condições socioeconômicas permitem garantir uma habitação planejada, adequada ao clima tropical,que minimizem ou anulem o desconforto térmico. A localização e as condições residenciais podem ser determinantes. Destaque para o condomínio fechado de alto padrão construtivo "Florais", com registro de melhores índices de conforto térmico, pela proximidade do espaço rural e densa vegetação no entorno. Uma boa estrutura, com paredes grossas, laje e cobertura com material de alto albedo, pode amenizar o desconforto térmico. Na escala do microclima, ou seja, no ambiente interno, há a possibilidade de equipar a residência com climatizador, ar condicionado, ventiladores, piscinas, entre outros. 
XVII Simpósio Brasileiro

de Geografia Fisica Aplicada

I Congresso Nacional de Geografia Física
OS DESAFIOS DA GEOGRAFIA FÍSICA NA FRONTEIRA DO CONHECIMENTO

Instituto de Geociências - Unicamp

Campinas - SP

28 de Junho à 02 de Julho de 2017

Por outro lado, os bairros de menor renda (setores cor mais escura), indicam precária condição socioeconômica, que geralmente se reflete em habitações totalmente inadequadas e ineficientes em garantir conforto térmico, seja para o frio, seja para o calor, denunciando onde estão aqueles que realmente estão mais vulneráveis ao desconforto térmico, pelas condições precárias de vida. Com renda domiciliar (familiar) de até 1 salário mínimo mensal, torna-se impossível prover a habitação de estrutura ideal de garantia de conforto térmico, para uma realidade socioeconômica de quem busca meios para garantir a própria sobrevivência.

\section{Considerações Finais}

A partir deste experimento, conclui-se que a cidade é capaz de produzir um clima, particularmente urbano. No episódio analisado, foi registrada uma ICU de $11^{\circ} \mathrm{C}$, que refletiu em precárias condições de conforto térmico para praticamente toda a cidade. Entretanto, ao avaliar a situação socioeconômica, representada espacialmente, é possível problematizar a mercantilização do conforto térmico na lógica de produção do espaço urbano. Os grupos sociais com melhores condições socioeconômicas têm condições de garantir seu conforto térmico por meio de habitações planejadas, desde o tipo de material até os equipamentos como: piscinas, ar condicionado e climatizadores. Por outro lado, outra parcela da população tem severas limitações econômicas que lhes permitam as mesmas condições micro-climáticas de conforto térmico. Ficou evidente a relevância da Geografia do Clima nas análises do clima urbano, tendo em vista que, ainda que o clima compartilhado por todos moradores da cidade se estabeleça de forma homogênea, a sociedade se estrutura de forma heterogênea e, por isso, os efeitos do clima serão diferenciados, conforme o nível de vulnerabilidade de cada grupo social.

\section{Agradecimentos}

Agradecemosaoapoioinstitucional do InstitutoBrasileiro de Geografia e Estatística (IBGE), na forma da licençacapacitação e à Fundação de Amparo à Pesquisa no Estado de São Paulo (FAPESP) pelabolsaconcedida, através do Processonúmero 2016 / 03599-9.

\section{8. Bibliografia}

ALEIXO, Natacha Cintia Regina. Pelas lentes da climatologia e da saúde. Tese (Doutorado em Geografia) Universidade Estadual Paulista Júlio de Mesquita Filho, Fundação de Amparo à Pesquisa do Estado de São Paulo. 2012.

AMORIM, M. C. C. T. Climatologia e Gestão do Espaço Urbano. In Mercator. Número especial, dez/2010. P. 71 a 90. 
AMORIM, M.C.C.T. Intensidade e forma da ilha de calor urbana em Presidente Prudente/SP: Episódios de Inverno. Geosul, UFSC - Florianópolis, v. 20, n. 39, p. 65-82, 2005.

ARNFIELD, A. J. Two decades of urban climate research: a review of turbulence, exchanges of energy and water, and the urban heat island. InternationalJournalofClimatology, v. 23, n. 01, p. 1-26, 2003.

AYOADE, J. O. Introdução a climatologia para os trópicos. Tradução de Maria Juraci Zani dos Santos. Rev. de Suely Bastos. Coord. Editorial de AntonioChristofoletti. 5a. Ed. Rio de Janeiro: Bertrand Brasil, 1998. 332p.

CAMARGO, Maristela Gomes de. FURLAN, Maria Montserrat Diaz Pedrosa. Resposta Fisiológica do Corpo às Temperaturas Elevadas: Exercício, Extremos de Temperatura e Doenças Térmicas. In Revista Saúde e Pesquisa, $v$. 4, n. 2, p. 278-288, maio/ago. 2011.

FIALHO, Edson Soares. Ilha de Calor: Reflexões acerca de um conceito. In ACTA Geográfica, Boa Vista, Ed. Esp. Climatologia Geográfica, 2012. pp.61-76

FROTA, A.B.\& SCHIFFER, S.R. Manual do Conforto Térmico. 5a ed. São Paulo: Studio. Nobel, 2001.

GARCÍA, F. F. Manual de climatologia aplicada: clima, medio ambiente y planificación. Madrid: Editorial sínteses. 1985.

GOMES, M. A. S.; AMORIM, M. C. C. T. Arborização e conforto térmico no espaço urbano: estudo de caso nas praças públicas de Presidente Prudente (SP). Caminhos de Geografia, v. 7, n. 10, p. 94-106, set. 2003.

HARVEY, David. A produção capitalista do espaço. São Paulo: Annablume, 2005.

IBGE - Instituto Brasileiro de Geografia e Estatística. Download. Geociências. Disponível em $<$ http://downloads.ibge.gov.br/downloads_geociencias.htm> Acesso em 16/11/2016.

LEFEBVRE, Henri. A produção do espaço. Tradução: Grupo "As (im) possibilidades do urbano na metrópole contemporânea, do Núcleo de Geografia Urbana da UFMG (do original: La production de l'espace. $4^{\mathrm{a}}$ ed. Paris: EditionsAnthropos, 2000). Primeira versão: início - fev. 2006.

LOMBARDO, Magda Adelaide. Ilha de calor nas metrópoles: o exemplo de São Paulo. Editora Hucitec com apoio de Lalekla S.A. Universidade do Texas Comércio e Indústria, 244 páginas 1985

MAITELLI, Gilda Tomasini. O Clima. In Geografia de Mato Grosso: Território, Sociedade e Ambiente. Gislaene Moreno e Tereza Cristina Souza Higa (Orgs.) Cuiabá: Entrelinhas, 2005. P. 238-249.

MONTEIRO, Carlos A. F. Teoria e clima urbano. Série "Teses e Monografias n 25". São Paulo: IGEOG/USP, 1976. 181p.

10 NASA. NOAA Analyses Reveal Record-Shattering Global Warm Temperatures in 2015. Disponível on line $\quad$ em.https://www.nasa.gov/press-release/nasa-noaa-analyses-reveal-record-shattering-global-warmtemperatures-in-2015. Acessoem 20/01/2016.

OKE, T. R. (1976) The distinction between canopy and boundary-layer urban heat islands, Atmosphere, 14:4, 268-277

OKE, T. R. Boundary Layer Climates. London: Methuem\& Ltd. A. Halsted Press Book, John Wiley \& Sons, New York, 1978, 372p.

ROSS, J. L. S. Geomorfologia, Ambiente e Planejamento. São Paulo, Ed. Contexto, 1990.

SANT'ANNA NETO, João Lima. Da Climatologia Geográfica à Geografia do Clima Gênese, Paradigmas e Aplicações do Clima como Fenômeno Geográfico. In Revista da ANPEGE. v. 4, 2008 
SANT'ANNA NETO, JOÃO LIMA. Por uma Geografia do Clima: Antecedentes históricos, paradigmas contemporâneos e uma nova razão para um novo conhecimento. Lab. De Climatologia. Depto de Geografia da FCT/UNESP. 2001. In Terra Livre. São Paulo. N.17 p. 49-62. Disponível online em http://www.ambiente.sp.gov.br/wp-content/uploads/cea/Texto_Neto.pdf. Acesso em 05/12/2015.

SANTOS, Milton. Por uma outra globalização: do pensamento único à consciência universal. 6a.edição. Editora Record. Rio de Janeiro. São Paulo. 2001

SORRE, Maximilien. Les fondements biologiques de la Géographie Humaine: essai d'une écologie de l'homme. Paris: Armand Colin, 1943, 440 p.

SOUZA, Débora Moreira. NERY, Jonas Teixeira. O Conforto térmico na perspectiva da Climatologia Geográfica. In Geografia (Londrina), v. 21, n.2. p.65-83, maio/ago. 2012. Disponível online em http://www.uel.br/revistas/uel/index.php/geografia/article/view/9798. Acessoem 14 fev 2017.

THOM, E.C. \& BOSEN, J.F.The discomfort index. Weatherwise. 1959; № 12, p. 57 - 60.

TORTORA, Gerard J. DERRICKSON, Bryan. Corpo Humano. Fundamentos de Anatomia e Fisiologia. 675 p. Editora Artmed. 10. ed. 2017. Porto Alegre RS.

VIANA, Simone Scatolon Menotti. Conforto Térmico nas Escolas Estaduais de Presidente Prudente/SP.(Tese de Doutorado). Faculdade de Ciências e Tecnologia. Universidade Estadual Paulista "Julio de Mesquita Filho" Campus Presidente Prudente SP. 2013 